\title{
Repetition priming with Japanese Kana scripts in word-fragment completion
}

\author{
SHIN-ICHI KOMATSU \\ Kagawa University, Takamatsu, Japan \\ and \\ MIKA NAITO \\ Tokyo Metropolitan University, Tokyo, Japan
}

\begin{abstract}
Manipulating two types of Japanese Kana script, Katakana and Hiragana, we examined the effects of a script change between study and test on later word-fragment completion. Throughout three experiments, materials were composed of foreign loan nouns normally written in Katakana, but not in Hiragana, according to approved usage in Japanese. Experiment 1 demonstrated the reliable size of cross-script priming between Katakana and Hiragana. In Experiment 2, crossmodal priming was substantial when modality of presentation was changed from auditory to visual. In Experiment 3, generating a target word from its definition induced priming comparable in size to that in the prior reading condition. These results have been confirmed in the Hiragana test, as well as in the Katakana test, thereby suggesting that some conceptual and modalityindependent processes may also mediate repetition priming.
\end{abstract}

The concepts of implicit and explicit memory have been introduced by Graf and Schacter (1985) as useful descriptive terms to distinguish between two forms of memory: "Implicit memory is revealed when performance on a task is facilitated in the absence of conscious recollection; explicit memory is revealed when performance on a task requires conscious recollection of previous experiences" (p. 501). With regard to experimental situations, explicit memory is assessed by traditional recall and recognition tests, whereas implicit memory is closely related to repetition or direct priming, which refers to the facilitative effect of prior processing of a specific episode on performance in word-fragment completion, perceptual identification, and lexical decision. ${ }^{1}$ Recent research on memory has focused much attention on the relation between implicit and explicit memory. Richardson-Klavehn and Bjork (1988) and Schacter (1987) have extensively reviewed striking and stable dissociations between these two forms of memory, although some parallel effects have also been reported. In the present study, we concentrated on two issues concerning these dissociations: the effect of a study-test change in surface features and the effect of prior generation on implicit and explicit memory performance.

Some critical evidence for the differential effects of surface features on implicit and explicit memory has come from the findings on study-test modality shifts: Repetition priming is reduced by a change of presentation mo-

We thank Margaret Intons-Peterson, Daniel Schacter, Teresa Blaxton, Janet Gibson, and Endel Tulving for their valuable comments on this article. Correspondence should be addressed to Shin-ichi Komatsu, Faculty of Education, Kagawa University, 1-1 Saiwai-cho, Takamatsu, Kagawa 760, Japan. dality between study and test, whereas recall and recognition are either unaffected or slightly affected (e.g., Graf, Shimamura, \& Squire, 1985; Jacoby \& Dallas, 1981; Morton, 1979). These findings imply that implicit memory performance is mediated not by conceptual processes but by modality-specific processes. One problem concerning the effects of presentation modality has been left unsolved, however: There exists a substantial size of repetition priming even when presentation modality (visual vs. auditory) is changed between study and test. In regard to cross-modal priming, Richardson-Klavehn and Bjork (1988) reviewed 24 experiments from 14 studies and concluded that, in most of the experiments, repetition priming was reduced by a modality change, but not eliminated (e.g., Jackson \& Morton, 1984; Kirsner \& Smith, 1974). A few studies demonstrated very little or null effect of prior study on implicit memory tests in the cross-modality conditions (Clarke \& Morton, 1983; Jacoby \& Dallas, 1981). Thus, although cross-modal priming is not consistently confirmed in implicit memory tests, the previous studies on the modality shifts suggest that repetition priming may also involve some conceptual or semantic component.

In addition to the modality shifts, other aspects of surface features have been investigated extensively: typography (e.g., Jacoby \& Hayman, 1987; Roediger \& Blaxton, 1987a; D. L. Scarborough, Cortese, \& H. S. Scarborough, 1977), language (e.g., Durgunoglu \& Roediger, 1987; D. L. Scarborough, Gerard, \& Cortese, 1984; Watkins \& Peynircioglu, 1983), and word or picture form of referent (e.g., Warren \& Morton, 1982; Weldon \& Roediger, 1987). It was found that, although the size of priming was attenuated by the study-test change of surface features, there still remained reliable priming. Naito and Komatsu 
(1988), using Japanese nouns, have explored the effects of a script change. Most Japanese nouns can be written not only in Kanji but in Hiragana, and transcription from Kanji to Hiragana or from Hiragana to Kanji is also possible. Subjects were presented a list of nouns in either Kanji or Kana script and were then asked to perform a perceptual identification test in either of the following two conditions: one condition in which the script type matched between study and test and the other in which the script type mismatched. It was found that changing writing script between study and test attenuated repetition priming. The size of priming was substantial, however, even when the script type mismatched between study and test, thereby confirming reliable cross-script priming.

Differential effects of prior generation on implicit and explicit memory have been clearly demonstrated by Jacoby (1983): Generating a word from the antonym led to better recognition than did reading a word, which is known as the generation effect (Slamecka \& Graf, 1978), whereas prior reading produced greater priming in perceptual identification than did prior generation. Thus, a crossover interaction has emerged. The similar pattern of results has also been reported by Winnick and Daniel (1970), with free recall as an explicit test, and by Blaxton (1989), with fragment completion as an implicit test. Although the effects of prior generation were regarded as one of the clearest pieces of evidence for experimental dissociations between implicit and explicit memory, recent research has shown that prior generation does cause reliable priming in implicit memory tests. Using Japanese materials, Naito and Komatsu (1989) explored the effects of prior generation on a perceptual identification task. As a result, generating a target word in response to its definition produced reliable priming effects in subsequent perceptual identification and, more importantly, the size of priming induced by prior generation did not differ significantly from the size of priming by prior reading, thus providing a sharp contrast with the results of previous studies in the English literature (Jacoby, 1983; Roediger \& Blaxton, 1987b; Winnick \& Daniel, 1970). Moreover, several studies in the English memory literature have also revealed that generating a target word gives rise to a reliable size of priming on later implicit memory tests, although experimental procedures and materials have differed from each other (Gardiner, 1988; Hirshman, Snodgrass, Mindes, \& Feenan, 1990; Masson \& MacLeod, in press; Schwartz, 1989; Toth \& Hunt, 1990). Thus, it becomes a matter of concern whether the effects of prior generation on performance in implicit memory tests (referred to as conceptual priming) are substantial.

Theoretically, there is one possible account for such cross-modal, cross-script, and conceptual priming. Some researchers have attempted to explain cross-modal priming in terms of the use of a visual image: Imaging what a word would look like typed during auditory presentation produced the equivalent effects on later implicit tests to reading that word (Jacoby \& Witherspoon, 1982; Roediger \& Blaxton, 1987b; Schacter \& Graf, 1989). ${ }^{2}$
The interpretation in terms of the imaging strategy can accommodate several findings not only on cross-modal priming but also on cross-script and conceptual priming, assuming that subjects, even though not seeing the test script during the encoding phase, may image the written script, which is equivalent to the data presented in the test phase. The validity of these interpretations, however, has been questioned by Hashtroudi, Ferguson, Rappold, and Chrosniak (1988), who failed to demonstrate significant facilitation on performance in later perceptual identification when subjects were instructed to form the image of a written word during auditory presentation. Thus, it remains unsolved whether the interpretation in terms of the imaging strategy can apply to the phenomena of crossmodal, cross-script, and conceptual priming.

To investigate the validity of the explanation in terms of an imaging strategy, we conducted a series of experiments using the specificity of the Japanese writing system. The Japanese writing system is composed of two distinct orthographies: Kanji and Kana. Kanji is the logographic script used to represent lexical morphemes. Most content words (nouns, verbs, and adjectives) are typically written in Kanji. Kana is a speech-sound-based system in which each script represents a syllable of the language. Kana is further subdivided into Hiragana and Katakana. In modern Japanese writing, each Kana script has its own usage. Hiragana is used to write grammatical morphemes and certain native words. Hiragana is also used for writing content words in place of Kanji. By contrast, Katakana is exclusively used to write foreign loan words. That is, Japanese content words are normally written in Kanji or Hiragana, and foreign loan words are normally written in Katakana. ${ }^{3}$ Because Kana is the syllabic script, it is possible to write Japanese content words in Katakana and foreign loan words in Hiragana. But the practice is not to do so.

In the present study, we used foreign loan words as experimental materials and manipulated the script type of the materials between Katakana and Hiragana. Implicit memory was assessed by a word-fragment completion test through a series of experiments. As described above, foreign loan words are normally written in Katakana according to approved usage in Japanese. Because both forms of Kana (Hiragana and Katakana) are syllabic script, it is also possible to write these foreign loan words in Hiragana, if necessary. But it is orthographically unfamiliar and, thus, makes some unusual, exceptional impression on Japanese natives. It can be assumed that subjects who are presented the foreign loan words may image the Katakana script corresponding to the normal writing of these words, but they would seldom or never image the Hiragana script, which is orthographically unfamiliar. These manipulations make it possible to explore the validity of the explanation based on an imaging strategy to the phenomena of cross-script, cross-modal, and conceptual priming.

In Experiment 1, the foreign loan words were visually presented in either Katakana or Hiragana, and word- 
fragment completion was tested under the cross-script and matched-script conditions between study and test. In Experiment 2 , the foreign loan words were auditorily presented, and fragment completion was tested in either Katakana or Hiragana under the cross-modal conditions. In Experiment 3, the phenomena of conceptual priming were examined: Subjects were required to generate a foreign loan word in response to its definition, and fragment completion was given in either Katakana or Hiragana.

\section{EXPERIMENT 1}

In Experiment 1, two types of Japanese Kana script, Katakana and Hiragana, were manipulated between study and test phases. The subjects studied a list of foreign loan words in either Katakana or Hiragana and then performed a word-fragment completion test in which graphemic word fragments were presented in either Katakana or Hiragana. As introduced earlier, Naito and Komatsu (1988, Experiment 1) demonstrated the reliable size of cross-script priming between Kanji and Kana, although priming was greater in the matched-script condition. The similar pattern of cross-script priming has also been reported using the two types of visually distinct scripts, Hindi and Urdu (Brown, Sharma, \& Kirsner, 1984) and Roman and Cyrillic (Feldman \& Moskovljevic, 1987). Because both of the two distinct scripts were orthographically familiar in these previous studies, and, hence, one might have induced the visual image of the other, it is possible to explain the cross-script priming relying on the use of an imaging strategy.

Using the foreign loan words, we examined whether cross-script priming between Katakana and Hiragana was substantial and, if it were so, whether these phenomena could be explained by the imaging strategy. Because the foreign loan words are written in Katakana according to approved usage in Japanese, subjects in the Hiraganastudy condition may image the Katakana script, which corresponds to the normal writing of the word. In contrast, it would rarely happen that subjects in the Katakana-study condition image the Hiragana script during the encoding phase. Therefore, if the imaging strategy were adopted by the subjects, cross-script priming should be obtained in the Hiragana-study/Katakana-test condition, but not (or at least be reduced) in the Katakana-study/Hiragana-test condition.

\section{Method}

Design. The design was a $2 \times 2 \times 2$ mixed factorial, with two between-subject factors and one within-subject factor. The betweensubject factor was script type in study and test phases (Katakana and Hiragana for each phase), and the within-subject factor was type of test item (old and new).

Subjects. Seventy-two undergraduate students at Tokyo Metropolitan University participated in the experiment. All were native Japanese speakers. The subjects were assigned randomly to each of the four experimental conditions: Katakana-study/Katakana-test, Katakana-study/Hiragana-test, Hiragana-study/Katakana-test, and Hiragana-study/Hiragana-test, with $18,19,18$, and 17 subjects, respectively.
Materials. The materials consisted of 60 nouns of foreign loan words normally written in Katakana. Each word was made up of five to seven Katakana (or Hiragana) letters. Word fragments were constructed such that in five-letter words, two letters were blanked out, and in six- and seven-letter words, three letters were blanked out. The selection of the letters blanked out or presented in a word fragment was made on the basis of a pilot test, which ensured that each fragment allowed only one legitimate solution. Figure 1 shows the examples of materials written in Katakana and Hiragana.

These words were randomly divided into two subsets of 30 words: One subset was presented as a study list written in either Katakana or Hiragana, and the other was presented as new items only in the test phase. The choice of the study list and new items was counterbalanced across subjects except that, in the Katakana-study/Hiraganatest and the Hiragana-study/Hiragana-test conditions, one subset was assigned to 1 more subject than the other. An additional set of 10 foreign loan nouns was also selected as buffer items in the study phase. Each item was printed in black letters on a $9 \times 13 \mathrm{~cm}$ card. All 40 cards for 5 primacy buffer, 30 critical, and 5 recency buffer items were collated into a stack as the study list. Following the study, a word-fragment completion test was given in either Katakana or Hiragana. It consisted of the $\mathbf{3 0}$ words that had been presented in the study list and the 30 new words, in random order.

Procedure. The subjects in each of the four between-subject conditions were tested in a single group. They were told that they would see a series of words and would later be tested on their memory, although the nature of the memory test was not specified. A list of 40 words written in either Katakana or Hiragana was presented at a rate of one word every $5 \mathrm{sec}$ by way of a subject's turning over the cards at a signal from the experimenter. After the list presentation, the subjects received a cryptarithm as a distractor task for $5 \mathrm{~min}$. The fragment completion test was then given. The subjects were asked to complete each fragment into the first meaningful word that came to mind by filling the blanks with letters. The subjects were allowed to work on a fragment as long as they desired and to return to ones they could not complete on initial attempts. The completion test took about $15 \mathrm{~min}$.

\section{Results and Discussion}

Table 1 shows the probabilities of correct completion as a function of script type in the study and test phases

\begin{tabular}{|c|c|c|}
\hline Katakana & Hiragana & Translation \\
\hline アシスタント & あしすたんと & assistant \\
\hline カメレオン & かめれおん & chameleon \\
\hline キャンパス & きゃんばす & campus \\
\hline 午チャップ & 岵ち卫ぷ & ketchup \\
\hline コンパニオン & こんばにおん & companion \\
\hline ダイナマイト & だいなまいと & dynamite \\
\hline トライアングル & とらいあんら゙る & triangle \\
\hline ピラミッド & 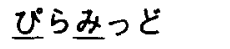 & pyramid \\
\hline ブルドッグ & ふるどっぐ & bulldog \\
\hline ボクシング & 正くしんぐ & boxing \\
\hline
\end{tabular}

Figure 1. Examples of experimental materials written in Katakana and Hiragana, together with their English translations. The letters missing from the fragments with which subjects were tested are underlined. 
Table 1

Probabilities of Correct Completion and Priming Values as a Function of Script Type in Study and Test Phases

\begin{tabular}{cccccc}
\hline & \multicolumn{2}{c}{ Script } & Type & & \multicolumn{2}{c}{ Type of Test Item } & \\
\cline { 5 - 6 } \cline { 5 - 6 } Study Phase & Test Phase & & Old & New & Priming \\
\hline \multirow{2}{*}{ Katakana } & Katakana & & .67 & .39 & .28 \\
& Hiragana & & .50 & .26 & .24 \\
Hiragana & Katakana & .64 & .41 & .23 \\
& Hiragana & .57 & .24 & .33 \\
\hline
\end{tabular}

and type of test item. To specify the effects of script type on priming, priming values (which are differences in performance between old and new items) are also presented in the last column of Table 1.

The results obtained for both matched- and cross-script conditions revealed a certain amount of priming effects. Statistical analyses confirmed this general observation. A $2 \times 2 \times 2$ analysis of variance (ANOVA), with a betweensubject factor of script type in the study and test phases and a within-subject factor of type of test item, was performed on the probabilities of correct completion. Differences between individual cells were examined by Tukey's tests, where significance levels were set at .05 . There was a significant main effect of type of test item $[F(1,68)=$ 344.06, $M S_{c}=2.669, p<.001$ ]. Subsequent Tukey's analyses revealed that correct probabilities of old items were significantly higher than those of new items in all study and test conditions. This indicates that significant priming was obtained even under the cross-script conditions, as well as under the matched-script conditions. In both study conditions, correct probabilities in the Katakanatest condition were higher than those in the Hiragana-test condition. This observation was reflected on the finding of another significant main effect of script type in the test phase $\left[F(1,68)=15.48, M S_{\mathrm{e}}=.659, p<.001\right]$. These results suggest that Katakana fragments were completed more easily than were Hiragana fragments, because the experimental materials were foreign loan words normally written in Katakana but not in Hiragana. The patterns of results differed between the two test conditions. There was a significant three-way interaction of script type in the study and test phases with type of test item $[F(1,68)=$ 5.35, $\left.M S_{\mathrm{e}}=.041, p<.03\right]$. In the Hiragana-test condition, performance on old items in the Hiragana-study condition was significantly higher than that in the Katakanastudy condition, whereas performance on new items did not differ between the two study conditions; in the Katakanatest condition, performance on both old and new items did not differ between the two study conditions.

Although significant values of priming were obtained in both cross-script and matched-script conditions, priming values were also affected by the script type in study and test phases: Priming in the Hiragana matched-script condition was higher than that in both of the cross-script conditions. This observation was confirmed by a $2 \times 2$ ANOVA on the priming values. There was a significant interaction between the script type in the study and test phases $\left[F(1,68)=5.35, M S_{\mathrm{e}}=.016, p<.03\right]$, but no main effect of these variables $\left(F_{\mathrm{s}}<1.33\right)$. Tukey's analyses revealed that, in the Katakana-study condition, the priming values between the Katakana and Hiragana tests did not differ significantly, but in the Hiragana-study condition, the values were significantly higher in the Hiragana test than in the Katakana test. In the Katakana-test condition, there was no difference between the script types in study, but in the Hiragana-test condition, the values of the Hiragana study were significantly higher than those of the Katakana study.

These results showed that reliable priming was consistently confirmed in both matched-script and cross-script conditions between the study and test phases, thereby replicating previous findings concerning script manipulations (Brown et al., 1984; Feldman \& Moskovljevic, 1987; Naito \& Komatsu, 1988). In the present experiment, however, differential effects of the script change on the size of priming were predicted between the two cross-script conditions, Katakana-study/Hiragana-test and Hiraganastudy/Katakana-test, following the explanation in terms of an imaging strategy during the encoding phase. That is, the subjects in the Hiragana-study condition might have imaged the Katakana script of a target word, whereas the subjects in the Katakana-study condition would have seldom or never imaged its Hiragana script, which is orthographically unfamiliar. The present result, therefore, that significant cross-script priming has been confirmed (especially in the Katakana-study condition) provides a strong contrast to the prediction in terms of the imaging strategy.

\section{EXPERIMENT $2 A$}

In Experiment 2A, the subjects heard a list of foreign loan words and then performed a word-fragment completion test in either Katakana or Hiragana. As mentioned in the introduction, the words could be pronounced the same regardless of the script type in which they were written. Thus, the script type in the test phase was manipulated between Katakana and Hiragana under the crossmodal condition from auditory to visual. In previous studies, it has been unclear whether the phenomena of cross-modal priming are substantial and whether the explanation based on an imaging strategy during encoding can accommodate these phenomena (e.g., Hashtroudi et al., 1988; Jacoby \& Witherspoon, 1982). In Experiment 2A, because the target words consisted of foreign loan words normally written in Katakana, it could be assumed that the imaged written script, if it happened at all, was exclusively Katakana, but not Hiragana. Using the Japanese Kana scripts, we examined the validity of the explanation of cross-modal priming based on the imaging strategy.

\section{Method}

Design and Materials. The design was a $2 \times 2$ mixed factorial. The between-subject factor was script type in test (Katakana and Hiragana), and the within-subject factor was type of test item (old and new).

Materials were the same as those used in Experiment 1, except that the study list was presented auditorily. The study list was a 
tape-recorded series of $\mathbf{4 0}$ words (5 primacy buffer, 30 critical, and 5 recency buffer items), which had been read by the experimenter at the rate of one word every $5 \mathrm{sec}$.

Subjects. The subjects were 66 undergraduate students at Tokyo Metropolitan University. All were native Japanese speakers. The subjects were assigned randomly to each of the two between-subject conditions: Half of the subjects were tested in Katakana, and the remaining half were tested in Hiragana.

Procedure. The subjects in each of the two between-subject conditions were tested in a single group. They were told that they would hear a series of words and would later be tested for memory, although the nature of the memory test was not specified. A taperecorded list of $\mathbf{4 0}$ words was presented. After the list presentation, the subjects received a cryptarithm as a distractor task for $5 \mathrm{~min}$, and the fragment completion test was given in either Katakana or Hiragana. The subjects were told to complete the fragments as meaningful words by filling the blanks with letters; the completion test took about $15 \mathrm{~min}$.

\section{Results and Discussion}

As shown in Table 2, the Katakana fragments (.428) were completed better than were the Hiragana fragments (.325), and, in both tests, old items (.514) were completed better than were new items (.239). These observations were supported by a $2 \times 2$ mixed ANOVA: There were significant main effects of script type in test $[F(1,64)=$ $\left.16.23, M S_{\mathrm{e}}=.347, p<.001\right]$ and type of test item $\left[F(1,64)=191.03, M S_{\mathrm{e}}=2.491, p<.001\right]$, but the interaction between the two factors was not significant $(F<1)$.

As mentioned in the introduction, previous findings on cross-modal priming have not been clear-cut: In some cases, the size of priming was reduced by modality shifts, but not eliminated (Jackson \& Morton, 1984; Kirsner \& Smith, 1974), whereas in other cases, modality shifts produced very little or null facilitation on performance in later implicit memory tasks (Clarke \& Morton, 1983; Jacoby \& Dallas, 1981). The results of Experiment 2A clearly show that cross-modal priming from auditory to visual is substantial.

It was possible to account for the phenomena of crossmodal priming in terms of the use of a visual image during the auditory study. In Experiment 2A, however, the size of cross-modal priming in the Hiragana-test condition was substantial and almost the same as in the Katakana-test condition, thereby posing a serious question about the validity of such an account. This was because the foreign loan words in Hiragana are orthographically unfamiliar and unacceptable and, thus, would not have been imaged during the auditory study.

One may argue that because of the inappropriate choice of words as experimental materials, the imaging strategy

Table 2

Probabilities of Correct Completion With Foreign Loan Words as a Function of Script Type in Test Phase and Type of Test Item

\begin{tabular}{ccc}
\hline & \multicolumn{3}{c}{ Type of Test Item } \\
\cline { 2 - 3 } Script Type & Old & New \\
\hline Katakana & .56 & .30 \\
Hiragana & .47 & .18 \\
\hline
\end{tabular}

itself might not have been working properly as postulated in the present study, thereby causing null effect of test script on cross-modal priming. Hence, normative data, such as frequencies, about the experimental materials were needed. The normative data were not available, however, to enable us to decide the exact frequencies for the foreign loan words in Japan. Instead, we examined the familiarities for the materials. Following the procedure by Umemoto, Morikawa, and Ibuki (1955), 65 subjects, who did not participate in the present experiments, rated the familiarity with each target word on a 6-point scale $(0=$ low, $5=$ high). It was shown that the foreign loan words used in the experiment had relatively high familiarities: The mean value of observed familiarities for 60 words was $4.017(S D=.898)$. This suggested that the subjects in Experiment 2A could have easily identified the target item as a foreign loan word and imaged its normal script.

In addition to the consideration of familiarities for the foreign loan words in Experiment 2A, we conducted a follow-up experiment, using Japanese native words, to examine further the validity of the imaging-strategy account for cross-modal priming. In Experiment 2B, the subjects heard a list of the Japanese words normally written in Hiragana; they were then tested in Hiragana or Katakana script. Hearing a Japanese native word, the subjects may image its Hiragana script, but not its Katakana script, because only Hiragana is used for the normal writing of that word.

\section{EXPERIMENT 2B}

\section{Method}

Design. The design was a $2 \times 2$ mixed factorial. The betweensubject factor was script type in test (Hiragana and Katakana), and the within-subject factor was type of test item (old and new).

Materials. The materials consisted of 60 nouns of Japanese native nouns normally written in Hiragana. Each word was made up of five to seven Hiragana (or Katakana) letters. A pilot study with the same subjects who rated familiarities for the foreign loan words in Experiment 2A was conducted: The subjects made a familiarity rating with each word on a scale from 0 to $5(0=l o w, 5=h i g h)$. It was revealed that the mean value of observed familiarities for the Japanese words was $4.192(S D=.766)$ and that there was no difference in familiarities between the foreign loan words used in Experiment $2 \mathrm{~A}$ and the Japanese words used in Experiment $2 \mathrm{~B}$ $[t(118)=1.145]$. Word fragments were constructed with the same procedure as that described in Experiment 1.

These words were randomly divided into two subsets of $\mathbf{3 0}$ words; one subset was presented auditorily as a study list, and the other was presented as new items only in the test phase. The choice of the study list and new items was counterbalanced across subjects. An additional set of 10 Japanese nouns was also selected as buffer items in the study phase. The study list was a tape-recorded series of 40 words ( 5 primacy buffer, 30 critical, and 5 recency buffer items), which had been read by the experimenter at the rate of one word every $5 \mathrm{sec}$.

Subjects and Procedure. The subjects were 36 undergraduate students at Tokyo Metropolitan University. All were native Japanese speakers. The subjects were assigned randomly to each of the two between-subject conditions: Half of the subjects were tested in Hiragana, and the remaining half were tested in Katakana.

The procecture was the same as that used in Experiment 2A, except that the materials used in the experiment were Japanese native words. 
Table 3

Probabilities of Correct Completion With Japanese Words as a Function of Script Type in Test Phase and Type of Test Item

\begin{tabular}{ccc} 
& \multicolumn{2}{c}{ Type of Test Item } \\
\cline { 2 - 3 } Script Type & Old & New \\
\hline Hiragana & .43 & .21 \\
Katakana & .42 & .19 \\
\hline
\end{tabular}

\section{Results and Discussion}

As shown in Table 3, the probabilities of correct completion of old items (.429) were higher than those of new items (.198). This observation was confirmed by a $2 \times 2$ mixed ANOVA: There was a significant main effect of type of test item $\left[F(1,34)=120.363, M S_{\mathrm{e}}=.957\right.$, $p<.001$ ], but neither the effect of script type in test nor the interaction between the two factors was significant $(F \mathrm{~s}<1)$.

Substantial cross-modal priming was again obtained in both Hiragana- and Katakana-test conditions. In addition, the size of priming was the same regardless of the script type. These results suggest that the imaging strategy account for cross-modal priming was not valid even when Japanese native words were used. This holds especially true because the familiarities for the Japanese words were relatively high, and, therefore, the subjects who heard the words could have easily imaged their Hiragana script but not their unfamiliar Katakana script; nevertheless, crossmodal priming occurred in the Katakana-test condition.

Compared with the results with foreign loan words in Experiment 2A, however, a different pattern of results was obtained with Japanese native words in the overall levels of performance between Katakana and Hiragana tests: Although performance in the Katakana-test condition was superior to performance in the Hiragana-test condition in Experiment 2A using foreign loan words, there was no significant difference between the two tests with Japanese native words. As described in the introduction, foreign loan words are normally written in Katakana, whereas Japanese native words are normally written in Hiragana or Kanji according to modern Japanese writing. This rule does not necessarily cover every case, however: There are also some exceptional cases where only one type of script is available, such as writing on a Kana typewriter or sending a telegram, and all words including Japanese natives are written in Katakana, but not in Hiragana or Kanji. In contrast, foreign loan words are exclusively written in Katakana, except for a specially complicated case like the experimental situations of this study. Thus, although we have used the same term "normally" for describing the writing rules of foreign loan words and Japanese native words, the acceptabilities of these rules differ from each other in some degree. This may have caused the difference in overall performance on completion tests between foreign loan words and Japanese native words.

\section{EXPERIMENT 3A}

In Experiment 3A, the two types of encoding tasks were manipulated by making subjects read a foreign loan word visually presented or generate it from its definition, and then a word-fragment completion test was given in either Katakana or Hiragana. A number of previous studies in the English memory literature (Jacoby, 1983; Morton, 1979; Roediger \& Blaxton, 1987a; Winnick \& Daniel, 1970) have found that prior generation produces little or no effect on later implicit memory tests. In contrast, Naito and Komatsu (1989) demonstrated that generating a Japanese word normally written in Kanji from its definition facilitated performance on subsequent perceptual identification of the word exposed in Kanji, thereby confirming a substantial amount of conceptual priming.

The results obtained by Naito and Komatsu (1989), however, may be explained in terms of the use of an imaging strategy: Even when a target word was not presented visually, the subjects required to generate the word may have formed its visual image of Kanji script corresponding to the test script in later identification. Thus, an important question that arises here is whether or not conceptual priming can be induced by prior generation under the condition where subjects cannot use the imaging strategy properly.

In Experiment 3A, we employed foreign loan words that are normally written in Katakana but not in Hiragana and asked the subjects to generate them from their definitions. If the subjects used the imaging strategy, they would image the Katakana script of the target word, but not the Hiragana script, because only the Katakana script is orthographically acceptable and familiar, following Japanese usage. It was predicted, therefore, that if significant conceptual priming obtained by Naito and Komatsu (1989) were attributable to the use of the imaging strategy, prior semantic generation of foreign loan words should facilitate performance on Katakana fragments, but not on Hiragana fragments.

\section{Method}

Design. The experiment was a $2 \times 3$ mixed factorial design, with script type in the test phase (Katakana and Hiragana) as a betweensubject variable and type of test item (reading, generation, and new) as a within-subject variable.

Subjects. The subjects were $\mathbf{4 2}$ undergraduate students at Tokyo Metropolitan University; all were native Japanese speakers. Half of the subjects were assigned randomly to the Katakana-test condition; the remaining half were assigned to the Hiragana-test condition. Materials. The materials were 75 foreign loan words and the corresponding word fragments. All of the words were nouns made up of five to seven Katakana (or Hiragana) letters. A pilot study with 65 subjects showed that the mean value of familiarities for the target words was $4.891(S D=.11)$ on a 6-point scale $(0=$ low, $5=$ high). For the word completion test, graphemic word fragments written in either Katakana or Hiragana were constructed in the same way as described in Experiment 1, and each fragment allowed only one legitimate solution. 
For each of the 75 words, two types of encoding tasks were prepared: the task involving the reading of a target word and the task involving the generation of a target. In the reading task, a target word (written in Katakana) together with a particular Katakana letter was presented, and the subjects were asked to judge whether the target word contained the Katakana letter and to answer "yes" or "no." In the generation task, a brief definition of a target word, which was constructed by paraphrasing from Dai-jirin (Sanseido's Japanese dictionary, 1988), was presented; the subjects were asked to generate the appropriate word from the definition. A preliminary experiment with 16 subjects, none of whom participated in the present experiments, revealed that the mean probability that the target words would be correctly generated from the corresponding definitions was .946 .

The 75 words were divided into three equal subsets: One subset was assigned to each of the two types of encoding tasks, and the remaining one was presented as new items only in the test phase. The assignment of the subsets to the encoding and new-item conditions was counterbalanced across subjects so that each subset appeared equally often in each condition. Twelve or 13 of the Katakana letters in the 25 reading tasks were contained in the target words, and the remaining letters were not. Each item, consisting of a target word (written in Katakana) and a Katakana letter for the reading task or a definition for the generation task, was printed in black letters on a $13 \times 18 \mathrm{~cm}$ card. All 50 cards were stacked up as a study list. Preceding the study list, four additional words were presented for practice. Half of these were assigned to each of the two types of encoding tasks. Following the study, a word-fragment completion test was given in either Katakana or Hiragana. It consisted of the 50 words that had been presented in the study list and the 25 new words, in random order.

Procedure. The subjects were run individually. The subjects were informed that they were to perform two types of tasks about words in a long list. For the reading task, the subjects were asked to respond "yes" or "no"; for the generation task, they were told to generate the appropriate word from a definition and say it aloud. Except for these instructions, the subjects were informed of nothing about the subsequent memory test. After the instructions, the practice list of four items was given to acquaint the subjects with the procedure. Then, the 50 items-25 target words with Katakana letters and 25 definitions-were mixed up together and presented in random order at a rate of one every $8 \mathrm{sec}$. The subjects received a cryptarithm as a distractor task after the list presentation for $5 \mathrm{~min}$. The fragment completion test was then given in either Katakana or Hiragana. The subjects were asked to complete each fragment into the first meaningful word that came to mind by filling the blanks with letters. They were allowed from 10 to $20 \mathrm{~min}$ to perform the fragment completion test. ${ }^{4}$

\section{Results and Discussion}

The mean probabilities of wrong words or omissions for generation in the subjects tested on Katakana fragments and on Hiragana fragments were $.082(S D=.057)$ and $.086(S D=.064)$, respectively. Words for which such errors occurred in the study phase were eliminated from the scoring of fragment completion. Table 4 shows the probabilities of correct completion in Katakana and Hiragana for the three types of test items. The probabilities of correct completion in the Katakana test (.569) were higher than those in the Hiragana test (.404), and the correct probabilities in the reading condition (.572) and the generation condition (.528) were higher than those in the newitem condition (.359). These observations were supported by a $2 \times 3$ mixed ANOVA, which yielded significant main effects of script type in test $\left[F(1,40)=40.81, M S_{e}=\right.$
Table 4

Probabilities of Correct Completion as a Function of Script Type in Test Phase and Type of Test Item

\begin{tabular}{cccc}
\hline & \multicolumn{3}{c}{ Type of Test Item } \\
\cline { 2 - 4 } Script Type & Reading & Generation & New \\
\hline Katakana & .67 & .60 & .44 \\
Hiragana & .48 & .46 & .28 \\
\hline
\end{tabular}

$.855, p<.001]$ and type of test item $[F(2,80)=31.456$, $\left.M S_{\mathrm{e}}=.530, p<.001\right]$ but no interaction between the two factors $(F<1)$. Tukey's analyses specified the differences in performance between the three types of test items: Performance in the reading and generation conditions was significantly higher than performance in the new-item condition, whereas there was no difference between the reading and generation conditions.

The results clearly showed that generating a word from its definition facilitated performance on later fragment completion, and the size of priming in the generation condition was comparable to that in the reading condition, thereby suggesting that conceptual priming induced by prior generation is substantial. These results replicated the previous finding reported by Naito and Komatsu (1989) but offered a striking contrast to the previous findings in the English memory literature (e.g., Jacoby, 1983; Roediger \& Blaxton, 1987b).

One explanation of this incongruence concerning the effects of prior generation is that the substantial size of conceptual priming might have been attributable to the use of a visual image during the encoding phase. The present results, however, demonstrated that the account based on the imaging strategy cannot accommodate the phenomena of conceptual priming, because substantial priming was confirmed even when the test script of a word fragment was orthographically unfamiliar, as was the case in the Hiragana test, and thus would seldom or never have been imaged during prior generation.

The results might be interpreted in another way, however: The same size of priming was obtained in both the reading and generation conditions because the subjects might have used explicit memory strategies during the completion test. ${ }^{5}$ Bowers and Schacter $(1990)$ have shown that the use of explicit memory strategies during an implicit completion test results in an enhanced ability in explicit remembering and thus produces a higher level of performance for semantically encoded words than for structurally encoded words (see Schacter, Bowers, \& Booker, 1989, for discussion of similar issues). This may hold especially true when the experimental procedure in the study phase, as employed in Experiment 3A, mixed the read and generate trials such that they were randomly presented together to the subjects. In previous studies, experimenters blocked these conditions and demonstrated little or no priming effect of prior generation on implicit memory tests (e.g., Blaxton, 1989). Because the subjects in Experiment $3 \mathrm{~A}$ were having to generate items on half of trials during study, the task demands of reading and 
generation may not have differed virtually from each other. The subjects may have adopted a mode of thinking about the meaning of all of the items as they were presented, and the performance levels obtained may have reflected primarily semantic or elaborative processing, from which explicit memory strategies benefit (cf. Craik \& Tulving, 1975).

To rule out the possibility that there had been no real difference in task demands of the two types of encoding tasks and the possibility that the subjects had been using explicit memory strategies during the completion test, Experiment 3B was carried out using an explicit recognition test in place of the implicit completion test. The subjects in Experiment 3B performed the same study tasks as those used in Experiment 3A. They were then required to recognize the target foreign loan words written in either Katakana or Hiragana script. It has been extensively shown that performance on explicit recall or recognition is better when preceded by the generation of the target words than when preceded by the reading of the target words (e.g., Slamecka \& Graf, 1978) and that recognition performance is not influenced by differences in surface features of items, such as typography (e.g., Roediger \& Blaxton, 1987b).

If task demands in the study phase differed between generation and reading, prior generation should induce better recognition performance than would prior reading, regardless of script type in the test phase; if explicit memory strategies are not adopted in the implicit completion test, an experimental dissociation should occur between implicit completion performance and explicit recognition performance. In contrast, if task demands did not differ between generation and reading because of the mixed study trials, or if subjects used the same explicit memory strategies on implicit and explicit tests, the patterns of results would be expected to be the same on both the completion test in Experiment $3 \mathrm{~A}$ and the recognition test in Experiment 3B.

\section{EXPERIMENT 3B}

\section{Method}

Design and Materials. The experiment was a $2 \times 2$ factorial design: Script type in the test phase (Katakana and Hiragana) was a between-subject variable; type of study task (reading and generation) was a within-subject variable. Materials were the same as those used in Experiment 3A.

Subjects. Thirty-six undergraduate students at Kagawa University served as subjects; all were native Japanese speakers. Half of the subjects were assigned randomly to the Katakana-test condition; the remaining half were assigned to the Hiragana-test condition.

Procedure. The procedure in the study phase was identical to that employed in Experiment 3A, except that a 3-h retention interval was employed. ${ }^{6}$ Following a 5-min cryptarithm task, the subjects were told to return to the laboratory at some specified time $3 \mathrm{~h}$ after the study session. In the test phase, 75 words -50 words from the study list and 25 new words-were presented to the subjects in random order; they were asked to record which words had appeared in the study list.

\section{Results and Discussion}

The mean error rates for generation in the subjects tested with Katakana script and Hiragana script were .071 $(S D=.051)$ and $.081(S D=.054)$, respectively. Words for which such errors occurred in the study phase were eliminated from the scoring of recognition memory.

As shown in Table 5, the hit rates in the generation condition (.889) were higher than those in the reading condition (.576), but there was no difference in the hit rates between the Katakana test (.738) and the Hiragana test (.727). These observations were confirmed by a $2 \times 2$ mixed ANOVA, which yielded a significant main effect of type of study task $\left[F(1,34)=220.664, M S_{c}=1.772\right.$, $p<.001]$; however, neither the effect of script type in the test phase nor the interaction between the two factors was significant $\left(F_{\mathrm{S}}<1\right)$. The false-alarm rates also failed to show the effect of script type: There was no difference in the false-alarm rates between the Katakana test $(.082)$ and the Hiragana test $(.064)[t(34)=.591]$.

It was clearly shown that recognition performance was reliably better when preceded by generation than when preceded by reading, regardless of script type in the test phase, thereby suggesting that, even though the read and generate trials were mixed up during study, the task demands were different from each other. The pattern of these results has also made a sharp contrast with the case on the implicit completion test where no such difference was found between the reading and generation conditions. This implies that the subjects in Experiment 3A might not have used explicit memory strategies during the implicit completion tests.

We should also note the possibility that this dissociation may have reflected differences related to the different types of cues that were used on completion and recognition tests (i.e., fragment vs. whole item) and, thus, explicit memory may have mediated performance in implicit completion tests. Although it is difficult to rule out the possibility conclusively, there are two points to argue against it. First, Naito and Komatsu (1989) demonstrated the same pattern of experimental dissociations concerning the effects of prior generation between implicit and explicit memory, using perceptual identification and free recall tasks. This suggests that the experimental dissociation obtained in Experiments 3A and 3B is not limited to the testing situations in which word completion with fragment cues and recognition with whole items are used for assessing implicit and explicit memory, respectively. The second point concerns the instructions given at test. Hashtroudi

Table 5

Probabilities of Hits as a Function of Type of Study Task and Script Type in Test Phase

\begin{tabular}{ccc}
\hline & \multicolumn{2}{c}{ Type of Study Task } \\
\cline { 2 - 3 } Script Type & Reading & Generation \\
\hline Katakana & .59 & .88 \\
Hiragana & .56 & .89 \\
\hline
\end{tabular}


et al. (1988) have suggested that it is not only the type of information presented to subjects at test but the type of test instructions that determines whether a test is implicit or explicit. Throughout the experiments in the present study, the subjects were not given any information that the solutions of some fragments corresponded to study items, but they were instructed to complete each fragment into the first meaningful word that came to mind. Moreover, a 5-min criptarithm distractor task was inserted between study and test phases to disguise the nature of the subsequent completion test. We can conclude, therefore, that conceptual priming induced by prior generation is substantial and not attributable to the use of explicit memory strategies nor the invalidity of encoding tasks.

There remains another problem, which is related to retention intervals: To avoid ceiling effects, we adopted the 3-h retention interval between study and test, which contrasted the 5-min interval used in the fragment completion tests throughout the present study. The longer retention interval in the recognition test might have hidden the differential effects of script type on recognition memory performance. This possibility seemed unlikely. First, Ohta and Komatsu (1983), using 6-min retention intervals, have demonstrated no effect of script type on recognition memory: Manipulating script type between study and test, they found that recognition memory performance in the matched-script condition did not differ from that in the cross-script condition (see Roediger \& Blaxton, 1987b, for a similar result). Second, it has been widely accepted that explicit memory is mainly determined by conceptual-driven processing but not by data-driven processing (e.g., Jacoby, 1983).

\section{GENERAL DISCUSSION}

The main findings from the present experiments are as follows: (1) the reliable size of cross-script priming is demonstrated between Katakana and Hiragana, (2) crossmodal priming is substantial when presentation modality is changed from auditory to visual, and (3) generating a target from its definition induces reliable priming as well as does reading it. These results have been confirmed not only in the Katakana test but also in the Hiragana test.

One possible explanation of the reliable size of crossscript, cross-modal, and conceptual priming was the use of an imaging strategy. With respect to the effects of the imaging strategy on later implicit memory tests, however, the results reported by previous studies were not necessarily clear-cut (Hashtroudi et al., 1988; Jacoby \& Witherspoon, 1982; Roediger \& Blaxton, 1987a, 1987b; Schacter $\&$ Graf, 1989). The experimental procedure commonly adopted by such previous studies was to manipulate the instructions given prior to study: Implicit memory performance was compared between the imagery condition in which subjects were instructed to form a visual image for each target word and the nonimagery condition in which no such instruction was given. Hence, it has been unclear whether or not the subjects really followed these instructions given by an experimenter: All of the subjects in the imagery condition may not have used the imaging strategy, or some subjects in the nonimagery condition may have employed this strategy spontaneously.

In the present study, we manipulated the use of the imaging strategy in a different way, utilizing the specificity of the Japanese writing system. In modern Japanese writing, foreign loan words can be written in both Kana scripts, Katakana and Hiragana, but only Katakana script of the words is orthographically familiar and acceptable. Thus, if the imaging strategy were adopted during the encoding phase of a foreign loan word, its imaged script should be exclusively Katakana, but not Hiragana. Nevertheless, cross-script, cross-modal, and conceptual priming effects have been confirmed reliably in the Hiraganatest condition as well as in the Katakana-test condition, thereby indicating some limitations of the explanation based on the imaging strategy.

It should be noted that baseline performance in fragment completion differed between Katakana and Hiragana tests throughout the present experiments with foreign loan words: The Hiragana completion test was more difficult than the Katakana completion test. This suggests that the subjects' strategies for completing fragments may have been affected by a test-difficulty factor and thus may have inflated or deflated differentially performance of the Katakana and Hiragana tests. Although there is not sufficient evidence to reject such test-difficulty interpretations, the results from recognition memory tests in Experiment 3B may help in the elucidation of this problem. It could be assumed that if the test-difficulty factor affected memory performance differentially, the baseline difference between Katakana and Hiragana tests should be observed not only on fragment completion tests but also on recognition tests; nevertheless, no difference was found in recognition memory performance between Katakana and Hiragana tests.

These results led us to propose that some semantic or conceptual processes may also mediate repetition priming in fragment completion. As mentioned in the introduction, it has been widely supported that implicit memory heavily draws on sensory-perceptual processes, but little on semantic-conceptual processes. This view was supported in part by the results of the present study, because the script change produced some decrement in the size of priming in Experiment 1. We emphasize, however, that conceptual processing more closely involves implicit memory than has previously been considered, at least with Japanese materials. A similar suggestion has been made by Hirshman et al. (1990), who postulated the two separate semantic representations, perceptual semantics and elaborative semantics, the former of which is mediating performance in fragment completion and causes conceptual priming. Kirsner, Milech, and Standen (1983) have also assumed that repetition priming is determined at two levels of lexical representation, modality-specific unit and common modality-independent unit. Kirsner and Dunn (1985) have further unfolded their view as possibly four hierarchically organized levels of representation. It appears that semantic-conceptual and modality-independent 
processes draw on performance in fragment completion, thereby resulting in a substantial amount of cross-script, cross-modal, and conceptual priming (see also Naito \& Komatsu, 1988).

We should point out the problem remaining unsolved in this study. In Experiment 3A, prior generation caused reliable priming in subsequent fragment completion, and the size of priming in the generation condition did not differ from that in the reading condition. These results were consistent with the results in Naito and Komatsu (1989) but brought out a striking contrast to previous findings in the English literature (e.g., Jacoby, 1983; Roediger \& Blaxton, 1987a). The real cause of this difference still remains unclear. Although we tentatively proposed the involvement of conceptual processing in performance of implicit memory to explain the substantial facilitation induced by prior generation, the specificity of the Japanese writing system may also have been related to such incongruence.

Because linguistic descriptions in Japanese differ considerably from those in alphabetic writing systems such as English, these differences might have caused the incongruent results concerning the effects of prior generation between Japanese and English materials. Besner and Hildebrandt (1987) suggested, however, that psychological operations involved in lexical access have commonalities between Japanese Kana and alphabetic English. Hence, further study will be necessary to elucidate whether or not the incongruent results concerning conceptual priming can be attributed to the differences in language of experimental materials.

Another possible explanation of the incongruent results is that generating a target word in response to its semantic cues does induce conceptual priming in implicit memory tests even with English materials. A few recent studies in the English memory literature have confirmed the reliable size of conceptual priming caused by prior generation in certain conditions. Schwartz (1989) has demonstrated the differential effects of prior generation between word completion and perceptual identification tests: Generating a target word induced priming comparable in size to that produced by prior reading only when followed by a completion test, and not when followed by an identification test. In other studies, however, reliable conceptual priming has been confirmed even in the identification tests (Naito \& Komatsu, 1989; Toth \& Hunt, 1990). Furthermore, Masson and MacLeod (in press) have also shown the substantial size of conceptual priming in identification tests, using a wide variety of generation cues, and they proposed that little or no conceptual priming would be limited to some exceptional generation procedures, such as generating a target from its antonym or idioms (e.g., Jacoby, 1983), where the target becomes highly integrated with its context during encoding. This view fits well with the results of Experiment $3 A$ of the present study in which generation cues were composed of definitions of targets, but not antonyms or idioms (but see Blaxton, 1989; Roediger \& Blaxton, 1987b; Winnick \& Daniel, 1970). Using the specificity of the Japanese writing system, we have provided clear evidence that conceptual priming caused by prior generation is substantial and that an imagery-strategy account cannot accommodate the phenomena of conceptual priming; yet under what condition conceptual priming occurs remains unclear and thus constitutes an important problem for future research.

\section{REFERENCES}

Besner, D., \& Hildebrandt, N. (1987). Orthographic and phonological codes in the oral reading of Japanese Kana. Joumal of Experimental Psychology: Learning, Memory, \& Cognition, 13, 335-343.

Blaxton, T. A. (1989). Investigating dissociations among memory measures: Support for a transfer-appropriate processing framework. Joumal of Experimental Psychology: Leaming, Memory, \& Cognition, 15, 657-668.

Bowers, J. S., SChaCter, D. L. (1990). Implicit memory and test awareness. Journal of Experimental Psychology: Learning, Memory, \& Cognition, 16, 404-416

Brown, H., Sharma, N. K., Kirsner, K. (1984). The role of script and phonology in lexical representation. Quarterly Journal of Experimental Psychology, 36A, 491-505.

Clarke, R., Morton, J. (1983). Cross-modality facilitation in tachistoscopic word recognition. Quarterly Joumal of Experimental Psychology, 35A, 79-96.

Craik, F. I. M., \&ulving, E. (1975). Depth of processing and the retention of words in episodic memory. Joumal of Experimental Psychology: General, 104, 268-294.

Durgunoglu, A. Y., \& Roediger, H. L. (1987). Test differences in accessing bilingual memory. Joumal of Memory \& Language, 26, 377-391.

Feldman, L. B., \&oskovluevic, J. (1987). Repetition priming is not purely episodic in origin. Journal of Experimental Psychology: Learning, Memory, \& Cognition, 13, 573-581.

GARDINER, J. M. (1988). Generation and priming effects in wordfragment completion. Journal of Experimental Psychology: Leaming, Memory, \& Cognition, 14, 495-501.

Graf, P., SChacter, D. L. (1985). Implicit and explicit memory for new associations in normal and amnesic subjects. Journal of Experimental Psychology: Leaming, Memory, \& Cognition, 11, 501-518.

Graf, P., Shimamura, A. P., SQuire, L. R. (1985). Priming across modalities and priming across category levels: Extending the domain of preserved function in amnesia. Journal of Experimental Psychology: Learning, Memory, \& Cognition, 11, 386-396.

HamanN, S. B. (1990). Level-of-processing effects in conceptually driven implicit tasks. Journal of Experimental Psychology: Leaming, Memory, \& Cognition, 16, 970-977.

Hashtroudi, S., Ferguson, S. A., Rappold, V. A., \&hrosniak, L. D. (1988). Data-driven and conceptually driven processes in partialword identification and recognition. Journal of Experimental Psychology: Learning, Memory, \& Cognition, 14, 749-757.

Hirshman, E., Snodgrass, J. G., Mindes, J., Feenan, K. (1990). Conceptual priming in fragment completion. Journal of Experimental Psychology: Learning, Memory, \& Cognition, 16, 634-647.

JACKSON, A., MORTON, J. (1984). Facilitation of auditory word recognition. Memory \& Cognition, 12, 568-574.

JACOBY, L. L. (1983). Remembering the data: Analyzing interactive processes in reading. Joumal of Verbal Leaming \& Verbal Behavior, 17, 649-667.

JACOBY, L. L., \& DALLAS, M. (1981). On the relationship between autobiographical memory and perceptual learning. Joumal of Experimental Psychology: General, 110, 306-340.

JaCOBY, L. L., \& Hayman, C. A. G. (1987). Specific visual transfer in word identification. Journal of Experimental Psychology: Learning, Memory, \& Cognition, 13, 456-463.

JACOBY, L. L., \& WITHERSPOON, D. (1982). Remembering without awareness. Canadian Journal of Psychology, 36, 300-324.

KIRSNER, K., DUNN, J. (1985). The perceptual record: A common factor in repetition priming and attribute retention? In M. I. Posner 
\& O. S. M. Martin (Eds.), Attention and performance (Vol. 11, pp. 547-565). Hillsdale, NJ: Erlbaum.

Kirsner, K., Milech, D., Standen, P. (1983). Common and modality-specific processes in the mental lexicon. Memory \& Cognition, 11, 621-630.

KIRSNer, K., Smith, M. C. (1974). Modality effects in word identification. Memory \& Cognition, 2, 637-640.

MAsson, M. E. J., MAcLEOD, C. M. (in press). Re-enacting the route to interpretation: Enhanced perceptual identification without prior perception. Journal of Experimental Psychology: General.

MorTon, J. (1979). Facilitation in word recognition: Experiments causing change in the logogen model. In P. A. Kolers, M. E. Wrolstad, \& H. Bouma (Eds.), Processing of visible language I (pp. 259-268). New York: Plenum.

NaIto, M., KomatsU, S. (1988). Attributes of memory that mediate priming effects in perceptual identification. Japanese Journal of Psychology, 58, 352-358. (In Japanese, with English summary)

Narto, M., Komatsu, S. (1989). Effects of conceptually driven processing on perceptual identification. Japanese Psychological Research, 31, 45-56.

Онта, N., Komatsu, S. (1983). Priming effects in word-fragment completion under cross-script conditions [Summary]. Proceedings of the 25th Annual Convention of the Japanese Association of Educational Psychology, 25, 612-613. (In Japanese)

RAPPOLD, V. A., \& HASHTROUD, S. (1991). Does organization improve priming? Journal of Experimental Psychology: Learning, Memory, \& Cognition, 17, 103-114.

Ruchardoson-KLAVEHN, A., Bjork, R. A. (1988). Measures of memory. Annual Review of Psychology, 39, 475-543.

Roediger, H. L., Blaxton, T. A. (1987a). Effects of varying modality, surface features, and retention interval on priming in wordfragment completion. Memory \& Cognition, 15, 379-388.

Roediger, H. L., \& Blaxton, T. A. (1987b). Retrieval modes produce dissociations in memory for surface information. In D. S. Gorfein \& R. R. Hoffman (Eds.), The Ebbinghaus Centennial Conference (pp. 349-379). Hillsdale, NJ: Erlbaum.

SANSEIDO (1988). Dai-jirin [Sanseido's Japanese dictionary]. Tokyo: Sanseido.

Scarborough, D. L., Cortese, C., Scarborough, H. S. (1977). Frequency and repetition effects in lexical memory. Joumal of Experimental Psychology: Human Perception \& Performance, 3, 1-17.

Scarborough, D. L., Gerard, L., * Cortese, C. (1984). Independence of lexical access in bilingual word recognition. Joumal of Verbal Learning \& Verbal Behavior, 23, 84-99.

SCHACTER, D. L. (1987). Implicit memory: History and current status. Joumal of Experimental Psychology: Leaming, Memory, \& Cognition, 13, 501-518.

SCHACTER, D. L., BOWERs, J., \& BoOKER, J. (1989). Intention, awareness, and implicit memory: The retrieval intentionality criterion. In S. Lewandowsky, J. C. Dunn, \& K. Kirsner (Eds.), Implicit memory: Theoretical issues (pp. 47-65). Hillsdale, NJ: Erlbaum.

SCHACter, D. L., Graf, P. (1989). Modality specificity of implicit memory for new associations. Journal of Experimental Psychology: Learning, Memory, \& Cognition, 15, 3-12.

SCHWARTZ, B. L. (1989). Effects of generation on indirect measures of memory. Journal of Experimental Psychology: Learning, Memory, \& Cognition, 15, 1119-1128.

Slamecka, N. J., Graf, P. (1978). The generation effect: Delineation of a phenomenon. Journal of Experimental Psychology: Human Learning \& Memory, 4, 592-604.

Toth, J. P., HuNT, R. R. (1990). Effects of generation on a wordidentification task. Joumal of Experimental Psychology: Learning, Memory, \& Cognition, 16, 993-1003.

Umemoto, T., Morikawa, Y., \& Ibuki, M. (1955). Similarity and familiarity scales of Japanese adjectives. Kyoto University Research Studies in Education, 1, 85-116. (In Japanese)

W ARREN, C., Morton, J. (1982). The effects of priming on picture recognition. British Joumal of Psychology, 73, 117-129.

Watkins, M. J., Peynircioglu, Z. F. (1983). On the nature of word recall: Evidence for linguistic specificity. Journal of Verbal Learning \& Verbal Behavior, 22, 385-394.

WELDON, M. S., \& RoEDIGER, H. L. (1987). Altering retrieval demands reverses the picture superiority effects. Memory \& Cognition, 15 , 269-280.

WinNICK, W. A., DANIEL, S. A. (1970). Two kinds of response priming in tachistoscopic word recognition. Journal of Experimental Psychology, 84, 74-81.

\section{NOTES}

1. Blaxton (1989) has employed a different type of implicit memory test-the answering of general knowledge questions-and has obtained experimental dissociations from other implicit memory tasks. It appears that implicit memory tasks should be distinguished further between implicit data-driven and implicit conceptually driven, the latter of which, including general knowledge retrieval and category exemplar generation, shows patterns of performance similar to those of explicit memory tasks, such as free recall and recognition (see also, Hamann, 1990; Rappold \& Hashtroudi, 1991). Throughout the present study, however, we explored the implicit data-driven tasks for assessing implicit memory performance in accordance with most of the implicit memory literature.

2. The term image is used to represent the concept designated by a word in the imagery literature. The present study, however, has consistently used this term in a more restricted sense to refer to a visual representation of a written word, following the implicit memory literature.

3. In a strict sense, writing Japanese content words in Katakana is occasionally acceptable, whereas foreign loan words are exclusively written in Katakana. The detailed discussion is found later in Experiment 2B.

4. Throughout the present experiments, the word-fragment tests were run at a subject pace. In contrast, Jacoby (1983) ran a perceptual identification task at an experimenter pace that did not allow subjects choice or time for working on items. Thus, there might be a concern that the comparison between the results obtained in the present study and those by Jacoby (1983) is irrelevant because of the differences in the test procedures. It seems unlikely that implicit memory performance may depend critically on whether the test was run at a subject pace or an experimenter pace. This is because using an identification task at an experimenter pace, on the one hand, Naito and Komatsu (1989) observed reliable conceptual priming induced by prior generation; on the other hand, little conceptual priming was found in a fragment completion task at a subject pace (Roediger \& Blaxton, 1987b).

5. The explanation in terms of the use of explicit memory strategies may also accommodate the results of Experiments 1, 2A, and 2B: The substantial size of cross-script and cross-modal priming may have arisen because the subjects treated fragment completion as an explicit memory test. To rule out this possibility, we ought to demonstrate an experimental dissociation between implicit and explicit memory under conditions in which the same experimental manipulations and materials are used, but not the same testing procedures. Previous research has shown, however, little or no effect of the change of surface features, such as script (Ohta \& Komatsu, 1983) and modality (e.g., Graf et al., 1985; Roediger \& Blaxton, 1987b), on an explicit memory test. Thus, parallel effects were predicted with respect to the manipulations employed in Experiments 1, 2A, and 2B even when subjects did not use explicit strategies in implicit completion tests. In contrast, differential effects were predicted concerning the comparisons between reading and generation conditions, which enabled us to examine alternatively the possible role of explicit memory strategies in implicit completion tests.

6. To explore the effect of encoding tasks (generation or reading) on recognition memory performance, we had conducted a preliminary experiment using the same retention interval between study and test as that used in Experiment 3A, which indicated some ceiling effect on recognition memory performance, especially in the generation condition. There might be two possible ways to avoid the ceiling effect: to use another type of explicit memory test, such as free recall, or to lengthen the retention interval between study and test. It is impossible, however, to examine the effects of test script in a free recall test. Thus, the latter procedure was adopted.

(Manuscript received August 2, 1990; revision accepted for publication July 26, 1991.) 